\title{
Cost-Effective Control of a Quarantine Disease: A Quantitative Exploration Using "Design of Experiments" Methodology and Bio-Economic Modeling
}

\author{
Annemarie Breukers, Wopke van der Werf, Jack P. C. Kleijnen, Monique Mourits, and Alfons Oude Lansink
}

\begin{abstract}
First, fourth, and fifth authors: Department of Social Sciences, Business Economics Group, and second author: Department of Plant Sciences, Group Crop and Weed Ecology, Wageningen University, P.O. Box 8130, 6700 EW Wageningen, The Netherlands; and third author: Department of Information Systems and Management, Tilburg University, P.O. Box 90153, 5000 LE Tilburg, The Netherlands. Accepted for publication 4 March 2007.
\end{abstract}

\begin{abstract}
Breukers, A., Van der Werf, W., Kleijnen, J. P. C., Mourits, M., and Oude Lansink, A. 2007. Options for cost-effective control of a quarantine disease: A quantitative exploration using "design of experiments" methodology and bio-economic modeling. Phytopathology 97:945-957.

An integrated approach to control of quarantine diseases at the level of the plant production chain is complicated. The involved actors have different interests and the system is complex. Consequently, control policies may not be cost effective. By means of a bio-economic model for brown rot in the Dutch potato production chain, the efficacy of different

factors. Results show that brown rot incidence and economic consequences are determined predominantly by policy and sector factors and, to a lesser extent, by economic and exogenous factors. Scenario studies were performed to elucidate how the government and sector can optimize the cost-effectiveness of brown rot control. Optimal cost-effectiveness of control requires cooperation of the sector and government, in which case brown rot incidence can be reduced by $75 \%$ and the costs of control can be reduced by at least 2 million euros per year. This study demonstrates quantitatively the potential contribution of an integrated approach to costeffective disease control at chain level.
\end{abstract} control options was quantitatively analyzed. An impact analysis was performed using the methodology of "design of experiments" to quantify the effect of factors in interaction on incidence and costs of brown rot. Factors can be grouped as policy, sector, economic, and exogenous
Additional keywords: metamodeling, Ralstonia solanacearum, simulation model.
Integrated approaches to control plant pests and diseases have long since been acknowledged as being important. In the second half of the twentieth century, the concept of integrated pest management (IPM) gained wide acceptance. IPM is defined as "a decision support system for the selection and use of pest control tactics, singly or harmoniously coordinated into a management strategy, based on cost/benefit analyses that take into account the interests of and impacts on producers, society, and the environment" (19). IPM is practiced mainly at field scale, by individual farmers. By contrast, control of quarantine diseases generally focuses on the entire production chain. Unfortunately, at the chain level, an integrated approach to the control of quarantine diseases is uncommon. Control policies generally are designed from a policy point of view, and consist mainly of regulatory measures imposed by the government (9-11).

One important reason for this is that a production chain consists of many actors with different, possibly conflicting interests. It is unclear how these different interests are weighed into the design of control policies, if at all. Moreover, enforcement of measures is often based on qualitative rather than quantitative knowledge of their costs and effectiveness. Consequently, such policies may not be optimal from an epidemiological or economic point of view. An integrated approach at the chain level would imply taking into account the potential contributions and interests of the actors at different levels of the production chain. Implementation and scientific foundation of such an approach requires quantitative

Corresponding author: A. Breukers; E-mail address: Annemarie.breukers@wur.nl

doi:10.1094/PHYTO-97-8-0945

(C) 2007 The American Phytopathological Society knowledge of how actions of actors or groups of actors affect cost-effectiveness of disease control at the chain level.

Another reason for the lack of integrated approaches at the chain level is that, as disease prevalence and control take place at a larger scale, dispersal patterns of diseases and potential intervention points are less well understood (14). Whereas numerous models have been developed to support disease control at the field level $(6,12,15,28)$, relatively few models focus on disease control at the level of the production chain (25) - let alone models that account for the interests of different groups of actors in this chain. Disease dynamics at the chain level have been modeled at a fundamental level $(9,23,27)$. However, the resulting theoretical models have limited applicability in the practical environment of disease control (26).

This article provides a quantitative analysis of the possibilities for increasing the cost-effectiveness of quarantine disease control by combining actions at different levels in the chain. An impact analysis and scenario studies were performed with a mechanistic and individual-based bio-economic model that simulates the epidemiological consequences and cost-effectiveness of controlling brown rot (caused by Ralstonia solanacearum race 3, biovar 2) in the Dutch potato production chain. Parameters of the model represent policy options, characteristics of actors in the potato production chain (e.g., farmers and trading companies), and socioeconomic and environmental conditions. To date, it has been a matter of debate as to which factors are of crucial importance in determining the cost-effectiveness of control and how a more cost-effective control of brown rot may be achieved.

By means of the impact analysis, the effects of factors on the incidence and costs of brown rot are quantified. Here, the techniques of design of experiments (DOE) and regression meta- 
modeling were applied, following Kleijnen and Sargent (17). Scenario studies were performed to elucidate how different strategies of the government and the actors in the potato production chain affect the cost-effectiveness of brown rot control. These strategies were defined according to two objectives: (i) minimizing disease incidence and (ii) minimizing costs. The results presented in this article quantitatively demonstrate how an integrated approach can contribute to cost-effective control of quarantine diseases at the level of the production chain.

\section{THEORY AND APPROACHES}

The bio-economic model. The bio-economic model consists of a combined epidemiological and economic model. The epidemiological model simulates the spread of potato brown rot over potato farms and fields in the Netherlands during a sequence of years (3). The smallest entity in the model, whose behavior is modeled, is the potato lot. A lot is defined as a population of potato plants or tubers of common descent, being grown in one field under the same management or being processed or stored as a single unit. Infections can arise via three possible pathways: primary infection, horizontal transmission, and vertical transmission. Primary infection occurs through irrigation of a potato lot with contaminated surface water. A large proportion of Dutch waterways are contaminated with brown rot bacteria due to the presence of infected host plants, bittersweet (Solanum dulcamara), from which bacteria can enter the surface water continuously. Horizontal transmission occurs through direct contact or through indirect (i.e., machinery-mediated) contact between a healthy lot and an infected lot. Vertical transmission implies transmission of the disease as a result of clonal propagation of infected potato seed.

The epidemiological model is individual based and object oriented; it contains a large number of objects representing individual farms, fields, and potato lots. The processes of the production cycle are explicitly included in the model. During these processes, changes in the state of these objects may be caused by events. Examples of events are primary infection or detection of an infected lot. The model is spatially explicit; all objects have an $x$ and $y$ coordinate, enabling spatial analysis of brown rot incidence and dispersal. The model contains stochastic elements because most events have a probabilistic nature; therefore, their occurrence is subject to randomness. As a result, the model is able to represent the irregularities characteristic for brown rot dynamics. Development and validation of this model have been described elsewhere (3). An extensive technical description of the model code is given by Breukers et al. (4).

The economic model uses the output of the epidemiological model to quantify the corresponding annual costs of controlling brown rot as well as the losses resulting from its presence $(2,5)$. The economic model quantifies only those costs that are completely attributable to brown rot. It distinguishes three cost categories: structural costs, incidental costs, and export losses. Structural costs are incurred as a consequence of preventive measures, such as monitoring, and remain rather constant over time. Incidental costs are related to reactive measures, such as destruction of an infected lot and quarantine measures on contaminated farms following a disease incident. Thus, incidental costs depend on observed brown rot incidence. Export losses occur if importing countries lose confidence in the phytosanitary safety of Dutch seed potato tubers. Export losses may be induced by an extremely large number of detections in a particular year or by a relatively high number of detections in several successive years. Recovery from a temporary reduction in export volume may take several years, depending on the magnitude of the reduction.

The stochastic nature of the epidemiological model allows the bio-economic model to present both average results and variation between years in brown rot incidence and economic conse- quences. To generate accurate simulation outcomes, the impact analysis is based on 500 replicates for each simulated scenario. Each simulation replicate covers a period of 20 years, the first 5 years of which are discarded to allow the system to "settle in" from the initial conditions to the long-term level and year-to-year variability. This period of 20 years is sufficient to allow for observation of potential long-term effects of the scenario on the modeled system (3).

Impact analysis: DOE and metamodeling. The effects of model parameters on the simulated incidence and economic consequences of brown rot were estimated by means of metamodeling. A metamodel is a simple functional relationship between the simulation model's input parameters (also called factors) and a specific output variable (response) (16). This relationship can be estimated by means of regression analysis on the simulation inputs and output of a number of scenarios. The scenarios required for this estimation were selected through the techniques of DOE. DOE is an efficient method for performing an impact analysis because it allows for estimation of factor effects on the basis of a minimum number of scenarios. Furthermore, DOE enables the estimation of interactions among inputs (18).

Many different experimental designs exist; which one is chosen depends on the number and type of effects that need to be estimated. In the current impact analysis, main effects and two-factor interactions were quantified. Higher-order effects were not estimated because they are difficult to interpret and often have negligible magnitudes (16). In order to estimate unbiased main effects and two-factor interactions, two levels for each factor (standardized to -1 and +1 ) suffice. The scenarios required for estimation of main effects are given by a so-called resolution IV (R-4) design, whereas scenarios for estimation of two-factor interactions are given by an R-5 design (1). Mathematically, a metamodel with main effects and two-factor interactions is represented by equation 1 :

$$
y_{i, j}=\beta_{0}+\sum_{h=1}^{k} \beta_{h} x_{i, h}+\sum_{h=1}^{k-1} \sum_{h^{\prime}=h+1}^{k} \beta_{h, h^{\prime}} x_{i, h} x_{i, h^{\prime}}+e_{i, j}
$$

where $y_{i, j}$ represents the average simulation response of scenario $i$ in replication $j, x_{i, h}$ the level of factor $h$ in scenario $i, \beta_{0}$ the intercept (overall response), $\beta_{h}$ the main effect of factor $h, \beta_{h, h^{\prime}}$ the interaction between factors $h$ and $h^{\prime}(h=1, \ldots, k)$, and $e_{i, j}$ the fitting error of the regression model in replication $j$ of factor combination $i$. Whereas the bio-economic model has numerous outputs, a univariate regression metamodel such as equation 1 has only one response variable. Therefore, a unique metamodel was estimated for each model output of interest.

Metamodels were fitted (calibrated) by means of corrected least squares (CLS) (18). A more common method is ordinary least squares (OLS); however, this method assumes independent, normally distributed errors with zero expectation and constant variance. In the current application, the errors are heteroscedastic (i.e., variance is not constant), and they are correlated across scenarios because the set of initial seed used in the 500 replications is the same for each scenario. CLS corrects the variances of the $\beta$ s for the observed variances and covariances in simulation outputs. Significance of the estimated effects was tested through a Student's $t$ statistic (18).

Impact analysis: selection of factors and factor levels. Criteria for model parameters to be included in the impact analysis were (i) they potentially affect the incidence or economic consequences of brown rot, (ii) a change in their values within a time frame of 5 years is possible, and (iii) the current structure of the Dutch potato production chain is preserved if their values are changed. Applying these criteria, 33 factors were included in the R-4 design, divided into four categories: policy, sector, economic, and exogenous factors. Policy factors define control measures imposed by the government, such as sampling intensity of potato 
and quarantine measures imposed on affected farms. Sector factors represent structural and behavioral characteristics of actors in the potato production chain, such as the hygiene level, likelihood of disobeying brown rot regulations, and type of transport. Economic factors represent prices of inputs and products and costs of preventive and reactive measures. Exogenous factors describe social and environmental characteristics that are relevant for brown rot presence and control (e.g., climate) and the brown rot situation abroad.

An overview of all factors and their acronyms, default levels, upper levels, and lower levels is shown in Table 1. The first letter of each acronym indicates the factor category $(\mathrm{p}=$ policy, $\mathrm{s}=$

TABLE 1. Parameters included as factors in the impact analysis, with default, upper, and lower levels (factors levels that have more than one subdivision are given in Appendix III, Tables 4 to 6)

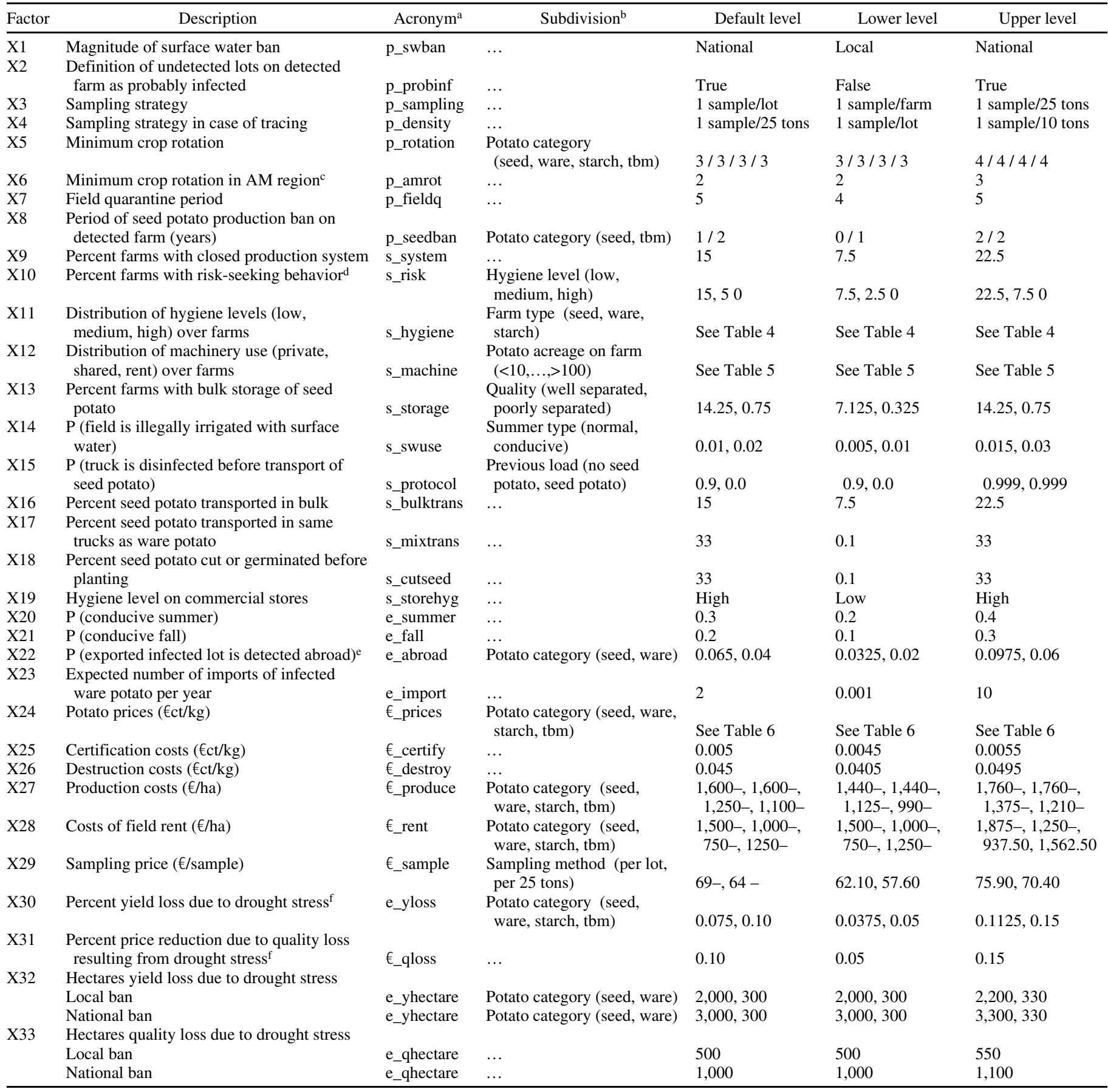

a The first character of an acronym indicates its category: $\mathrm{p}=$ policy factor, $\mathrm{s}=$ sector factor, $€=$ economic factor, $\mathrm{e}=$ exogenous factor.

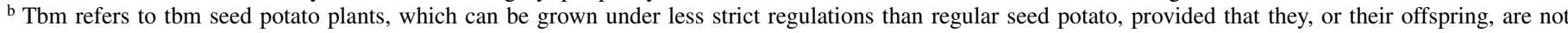
transported off the farm until harvested as starch potato tubers.

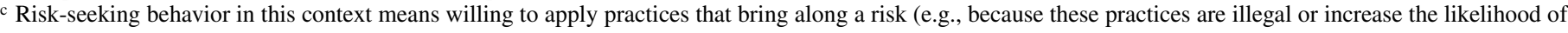
brown rot introduction or dispersal) if these practices may bring along (economic) benefits for the farmer.

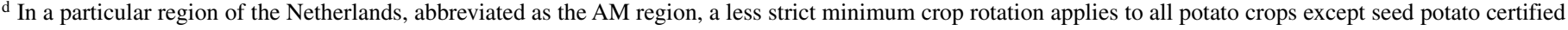
by the Dutch General Inspection Service (Nederlandse Algemene Keuringsdienst, NAK).

e Only seed and ware potato are exported.

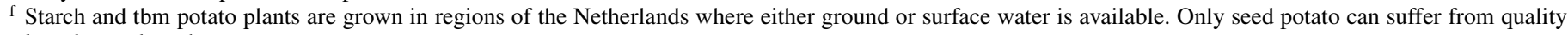
loss due to drought stress. 
sector, $€=$ economic, and e = exogenous factor). Default levels correspond to the factor level that currently os observed in practice. The upper and lower levels represent the maximum increase and decrease, respectively, that is realistic within a period of 5 years. Upper and lower levels are motivated in Appendix I.

An R-4 design for 33 factors consists of 72 scenarios. An R-5 design for the same number of factors contains $>1,000$ scenarios. Running this number of simulations would be very time consuming; therefore, we estimated two-factor interactions per response variable for the five factors with the largest significant $(P<0.05)$ main effects as demonstrated in the preceding R-4 design. This choice was based on the "strong heredity" principle, which states that factors that do not have an important main effect do not have important interactions either (29).

Impact analysis: selection of response variables. Response variables were selected using simulation results for the default scenario, which represents the brown rot policy and sector characteristics that currently apply in the Netherlands. Cumulative frequency distributions of the number of infections and incidental costs per year are shown in Figure 1. To distinguish between factors affecting the general level of these outputs and factors affecting the occurrence of extremes, two indicators are required for brown rot incidence and incidental costs. Because the distributions of both outputs are right-skewed, their shape is best represented by the median and the 90th percentile.

Structural costs remain constant over time at $\approx 6$ million euros per year for the default scenario. Export restrictions are observed in $11.2 \%$ of the years. Export restrictions cause losses of at least several million euros, resulting in an average loss of 0.8 million euros per year. Sector and policy representatives consider any level of export restrictions unacceptable; therefore, they are more concerned about the probability of export losses than about their size. In total, six response variables were selected for the impact analysis: median and 90th percentile of yearly number of infected lots, median of yearly structural costs, median and 90th percentile of yearly incidental costs, and frequency of years with export losses.

Impact analysis: metamodel validation. The objective of metamodeling was to quantify and rank the importance of factors and their interactions; the metamodels do not replace the bio-economic model. Therefore, a metamodel that provides a moderate level of explanation suffices (17). The metamodels are validated with respect to their accuracy in predicting simulation outputs of the bio-economic model; the validity of the bio-economic model itself has been addressed separately $(4,5)$.

The $R^{2}$ of the metamodels was calculated to determine the fraction of the variation explained by them. Next, a leave-one-out cross validation was performed. With leave-one-out cross validation, one scenario at a time is eliminated from the regression analysis, after which the reestimated metamodel is used to predict the simulation output for the omitted combination. Scatter plots of predicted values against simulation outputs and Pearson's linear correlation coefficient $(\hat{\rho})$ were used to characterize the accuracy with which the metamodels predict simulation outputs of the bioeconomic model.

R-5 designs for five factors are saturated (i.e., the number of effects to be estimated equals the number of factor combinations, leaving no degrees of freedom for validation) (20). Therefore, the original R-5 designs were extended with five extra scenarios. These scenarios also were used in the estimation of the metamodels, because-provided that they are not outliers-increasing the number of scenarios improves the accuracy of estimated parameters.

Scenario studies. In controlling brown rot, the sector and government have two main objectives: (i) minimizing brown rot incidence and (ii) minimizing costs. Because most measures that limit the incidence of brown rot cost money, there is a potential for trade-off between these objectives. Given the two objectives, three future strategies per group of actors are possible: (A) the importance of the objectives does not change (i.e., same as default), (B) the first objective gains greater importance, and (C) the second objective gains greater importance. Based on these strategies, nine scenarios were defined, representing all possible combinations of sector and government strategies (Table 2). Scenario codes indicate the sector and government strategy, respectively.

Factors and factor levels per scenario were selected according to the results of metamodeling. Only factors included in the top five important factors of at least one response variable were taken into account. It is assumed that the government can affect only policy factors, whereas actors in the sector can affect only sector factors. Brown rot incidence is minimized through factors that have a large impact on the yearly number of infections. The government can minimize costs of control by changing policy factors that have a large impact on structural or incidental costs. Actors in the sector can minimize costs through factors that affect yield or costs of production or labor. Here, individual actors in the sector are assumed to minimize primarily their own costs, rather than the costs of the sector as a whole.

Scenarios that increase the frequency of export losses compared with the default situation are unacceptable. Consequently, government and sector factors with a large impact on frequency of export losses cannot simultaneously be set at levels that increase the frequency of export losses. However, if the government and sector aim at contrasting objectives, the increased risk of export
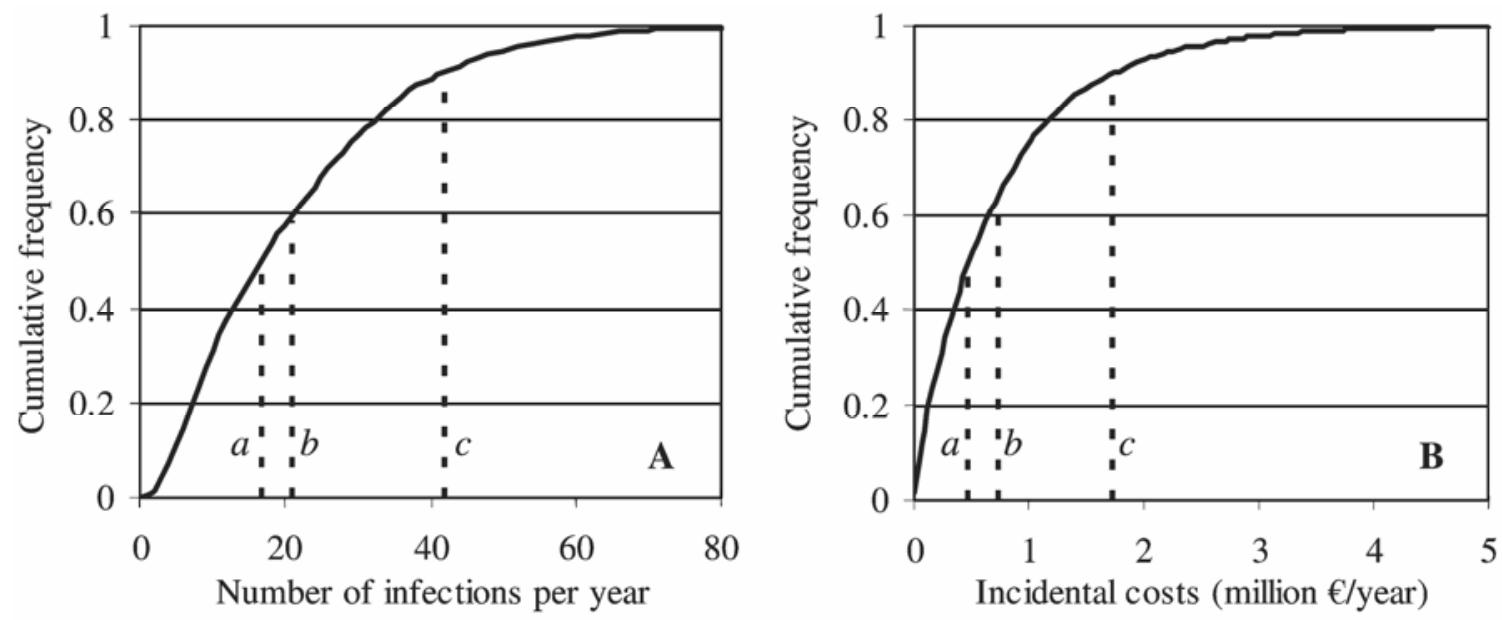

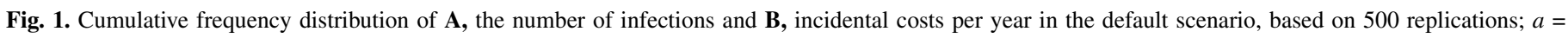
median, $b=$ mean, and $c=90$ th percentile. 
losses caused by modified government measures may be compensated for by the sector and vice versa. Therefore, two extra scenarios were included, which represent opposite objectives of the two groups of actors where frequency of export losses is not used as a limiting condition (Table 2, scenarios $\mathrm{C}^{\prime} \mathrm{B}$ and $\mathrm{BC}^{\prime}$ ).

\section{RESULTS}

Based on the estimated main effects, factors are ranked according to their impact on each response variable. Next, important interactions between factors are identified, after which the validity of the metamodels is discussed. Finally, the results of the scenario studies are analyzed to evaluate how different sector and government objectives affect the cost-effectiveness of control.

Ranking of factors. The main effects of the 10 most important factors per response variable, based on the R-4 design, are shown in Figure 2. Factors with a positive sign for a particular response variable cause an increase in that variable, compared with the default situation, when set at their upper value, and a decrease when set at their lower value; factors with a negative sign have opposite effects. Note that the default value of a factor does not necessarily lie in the center of the upper and lower level (i.e., at level " 0 "), and that factor effects presented in Figure 2 are the average effects measured over all levels of the other factors included. Thus the estimated effects may be different from the observed change in simulation output when changing a factor from its default to its upper or lower value.

Four of the six response variables show a considerable difference in effect size between the highest-ranked factors and lowerranked factors (Fig. 2A to $\mathrm{C}$ and $\mathrm{F}$ ). Thus, these response variables are largely determined by a few (at maximum, five) important factors. For five of the six response variables, the top five important factors are dominated by sector factors. These sector factors all affect, among others, the probability of primary infection through contaminated surface water. The observed importance of these factors is in agreement with an earlier observation that, in the default scenario, contaminated surface water is the most important infection source (3). Below, factor effects are discussed for each response variable.

Yearly number of infections (Fig. $2 A$ and B). The median and 90th percentile have the same four dominant factors, implying that these factors affect the entire distribution of brown rot incidence. They change the median by $\approx 10$ infections per year and the 90 th percentile by $\approx 20$ infections per year. In the default scenario, the two response variables have values of 16 and 41, respectively (Fig. 1A); thus, the impact of the highest-ranked factors on brown rot incidence is considerable.

Structural costs (Fig. 2C). The median of structural costs constituted the only response variable that is not dominated by sector factors and for which economic factors play a significant role. By far, the most important factor for this response variable is the sampling strategy, with an effect of $>2.5$ million euros. This effect is completely attributable to a change in the number of samples and, thus, sampling costs. Other high-ranked, moderately important factors are potato prices, the magnitude of yield loss in case of drought stress in the absence of irrigation, and the magnitude of the surface water ban imposed by the government. These three factors all affect the yearly losses from prohibition of the use of surface water.

Incidental costs (Fig. 2D and E). The difference in effect size between the first and 10th ranked factor is rather small for both the median and the 90th percentile. Thus, incidental costs are less strongly dominated by the highest-ranked factors. The effects range from $>0.1$ to 0.2 million euros per year for the median and from 0.2 to 0.6 million euros per year for the 90th percentile. Given the default values of 0.5 and 1.7 million euros, respectively, for these response variables (Fig. 1B), these impacts are modest. Thus, incidental costs are affected substantially by a wider range of factors than other outputs of the model; however, the sensitivity to change is, in relative terms, smaller than for the other response variables.

Frequency of export losses (Fig. 2F). The six highest-ranked factors are exactly the same as those for the median number of brown rot infections per year. This reflects the causal relationship between brown rot incidence and the occurrence of export losses. The most influential factors with respect to the frequency of export losses cause an increase or decrease of this frequency of between 5 and $10 \%$; thus, these effects were major compared with the default value of $11.2 \%$ for this response variable.

Identification of important interactions. The 10 most important main effects and interactions, based on the R-5 design, are shown in Figure 3. For all response variables, at least three factors have main effects that are more important than any interaction. Furthermore, factors with high-ranked main effects generally have higher-ranked interactions than factors with less important main effects. These results corroborate the strong heredity assumption based on which factors with a rank $<5$ were excluded from the R-5 design. Differences between the main effects estimated from the R-4 and R-5 designs are small, showing that the restriction to the five most influential factors has not compromised the estimation of their effects.

All positive interactions in Figure 3 involve factors whose effects have the same sign, whereas all negative interactions involve factors with opposite effect signs. This implies that all important interactions strengthen the main effects of the two factors involved (i.e., the two factors are more than additive). In practice, this means that, in a scenario where several factors are set at levels that cause an increase (or decrease) in cost-effectiveness, the total increase (decrease) in cost-effectiveness may be larger than expected on the basis of individual factor effects. For

TABLE 2. Scenarios for the government and the sector with corresponding factors and their levels ${ }^{\mathrm{a}}$

\begin{tabular}{|c|c|c|c|c|}
\hline Scenario & Sector objective & Adjusted factor levels & Government objective & Adjusted factor levels \\
\hline AA & Default & $\ldots$ & Default & $\ldots$ \\
\hline BA & Minimizing brown rot incidence & s_risk $=-1 ;$ s_hygiene $=+1 ;$ s_swuse $=-1$ & Default & $\ldots$ \\
\hline $\mathrm{CA}$ & Minimizing costs of control & s_system $=-1 ;$ s_risk $=+1$ & Default & $\ldots$ \\
\hline $\mathrm{AB}$ & Default & $\ldots$ & Minimizing brown rot incidence & p_sampling $=+1$ \\
\hline BB & Minimizing brown rot incidence & s_risk $=-1 ;$ s_hygiene $=+1 ;$ s_swuse $=-1$ & Minimizing brown rot incidence & p_sampling $=+1$ \\
\hline $\mathrm{CB}$ & Minimizing costs of control & s_system $=-1 ;$ s_risk $=+1$ & Minimizing brown rot incidence & p_sampling $=+1$ \\
\hline $\mathrm{AC}$ & Default & .. & Minimizing costs of control & p_swban $=-1 ;$ p_probinf $=-1$ \\
\hline $\mathrm{BC}$ & Minimizing brown rot incidence & s_risk $=-1 ;$ s_hygiene $=+1 ;$ s_swuse $=-1$ & Minimizing costs of control & p_swban $=-1 ;$ p_probinf $=-1$; \\
\hline $\mathrm{CC}$ & Minimizing costs of control & s_system $=-1 ;$ s_risk $=+1$ & Minimizing costs of control & p_swban $=-1 ;$ p_probinf $=-1$ \\
\hline $\mathrm{C}^{\prime} \mathrm{B}$ & Minimizing costs of control & $\begin{array}{l}\text { s_system }=-1 ; \text { s_risk }=+1 ; \text { s_hygiene }=-1 ; \\
\text { s_swuse }=+1\end{array}$ & Minimizing brown rot incidence & p_sampling $=+1$ \\
\hline $\mathrm{BC}^{\prime}$ & Minimizing brown rot incidence & s_risk $=-1 ;$ s_hygiene $=+1 ;$ s_swuse $=-1$ & Minimizing costs of control & $\begin{array}{l}\text { p_swban }=-1 ; \text { p_probinf }=-1 ; \\
\text { p_sampling }=-1\end{array}$ \\
\hline
\end{tabular}

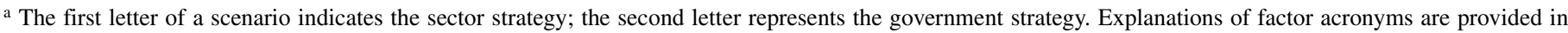
Table 1. 
instance, if the sector factors representing the probability of illegal use of surface water and of risk-seeking behavior (factors A and B) simultaneously reach a high value (Fig. 3D and F), additional costs of up to 100,000 euros per year may be incurred and the frequency of export losses may increase with another $5 \%$.

Many sector factors have important interactions with each other, which results from the fact that these factors have effects on the epidemiology of brown rot and are entangled with each other in the model. For instance, illegal irrigation is possible only at risk-seeking farms, because only these farms are assumed to disobey the law. Consequently, the factors representing probability of illegal irrigation at risk-seeking farms and number of farms with risk-seeking behavior interact. Important interactions also are observed between sector and policy factors. For instance, the policy factor determining sampling strategy (p_sampling) negatively interacts with sector factors that have a positive effect on brown rot incidence and vice versa. Similarly, sector factors which-due to their effect on brown rot incidence-have a positive effect on incidental costs positively interact with the policy factor determining which lots achieve the status "probably in-

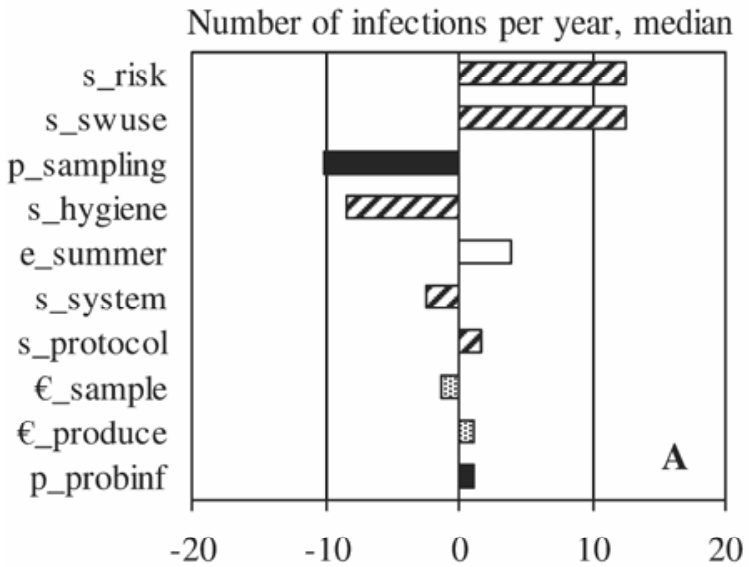

Structural costs, median (million €/year)

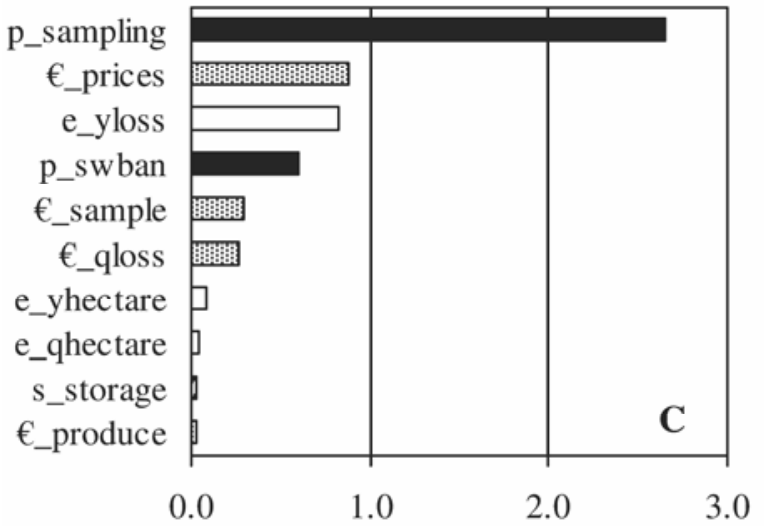

Incidental costs, 90th percentile (million €/year)

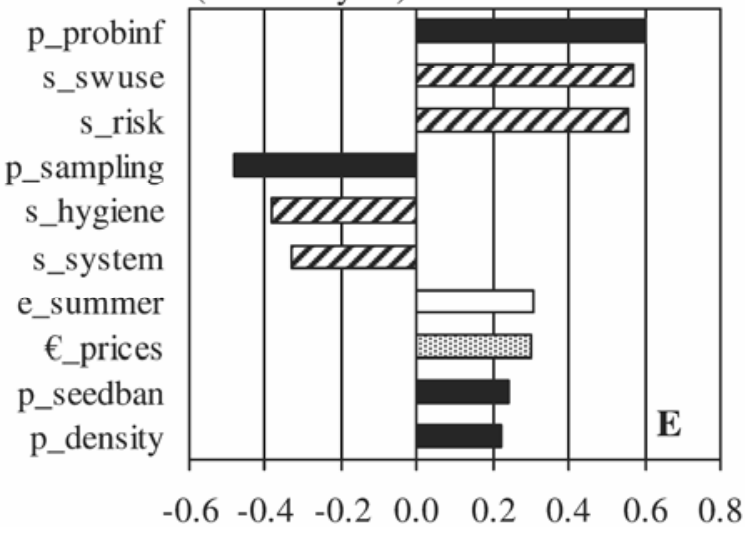

Number of infections per year, 90th percentile

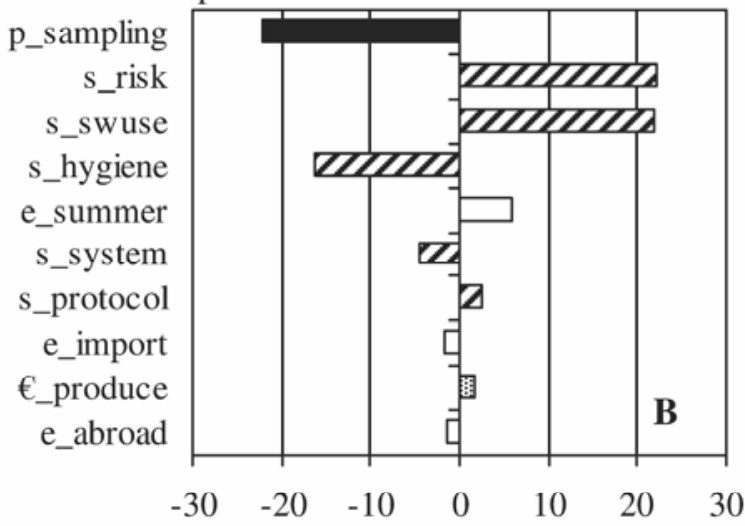

Incidental costs, median (million €/year)

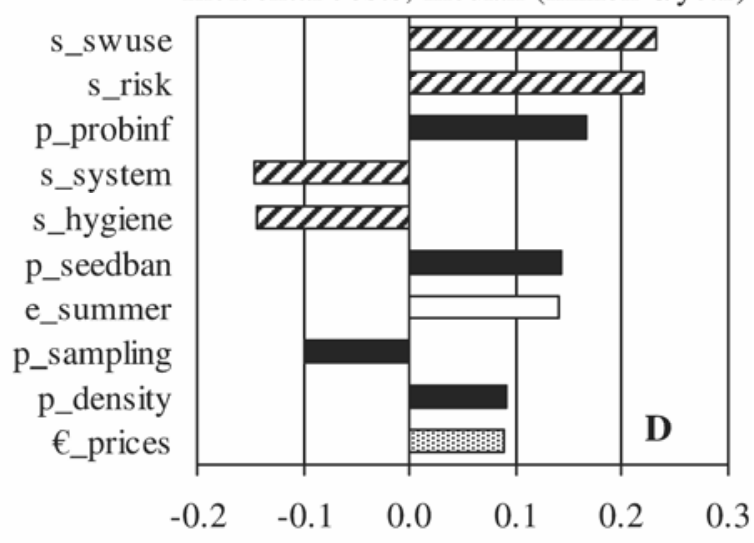

Frequency of export losses $(\%)$

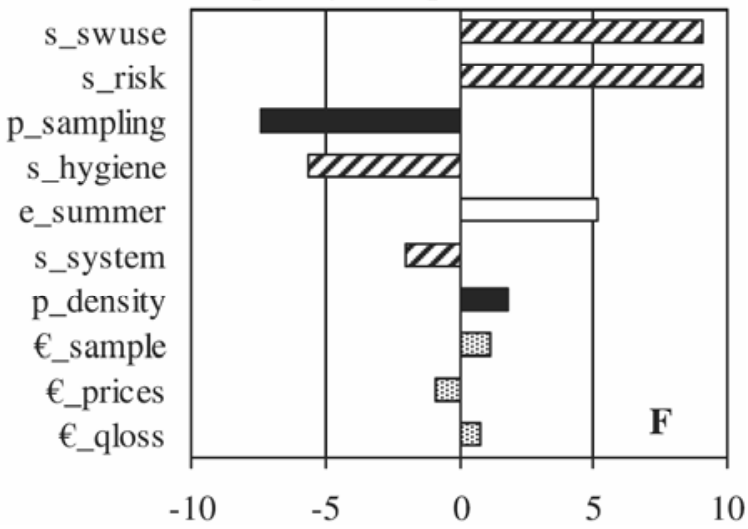

Fig. 2. Main effects of the factors ranked from 1 to 10 per response variable, based on the R-4 design (all significant at $P<0.05$ ). Explanation of bar patterns: black $=$ policy factor , cross-hatched $=$ sector factor, dotted $=$ economic factor, and white $=$ exogenous factor. Explanations of factor acronyms are provided in Table 1. 

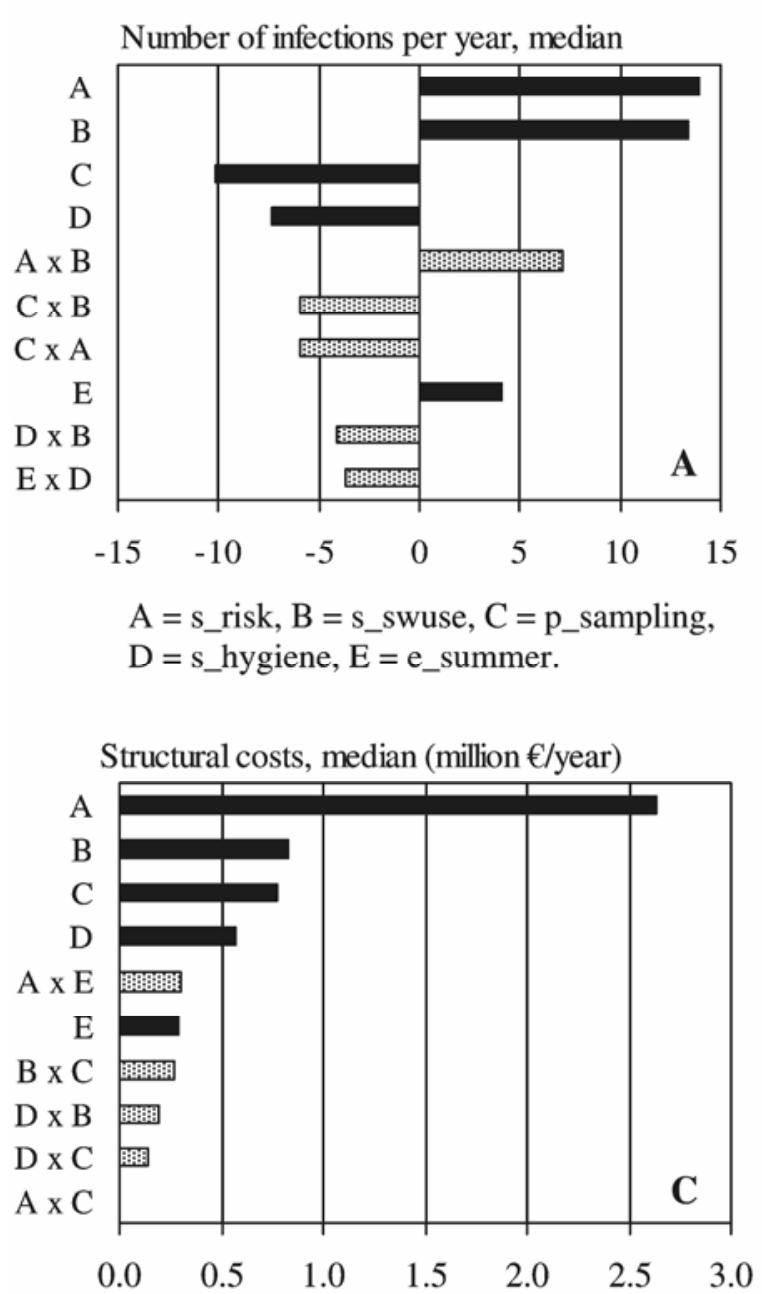

$\mathrm{A}=\mathrm{p} \_$sampling, $\mathrm{B}=€$ _prices, $\mathrm{C}=\mathrm{e} \_$yloss, $\mathrm{D}=\mathrm{p} \_$swban, $\mathrm{E}=€ \_$sample.

Incidental costs, 90 th percentile (million $€ /$ year)

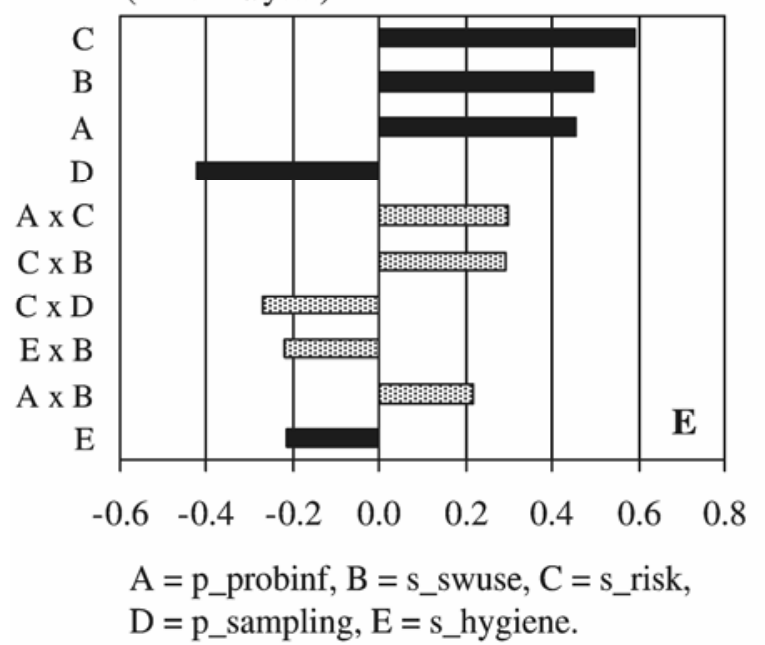

Number of infections per year, 90th percentile

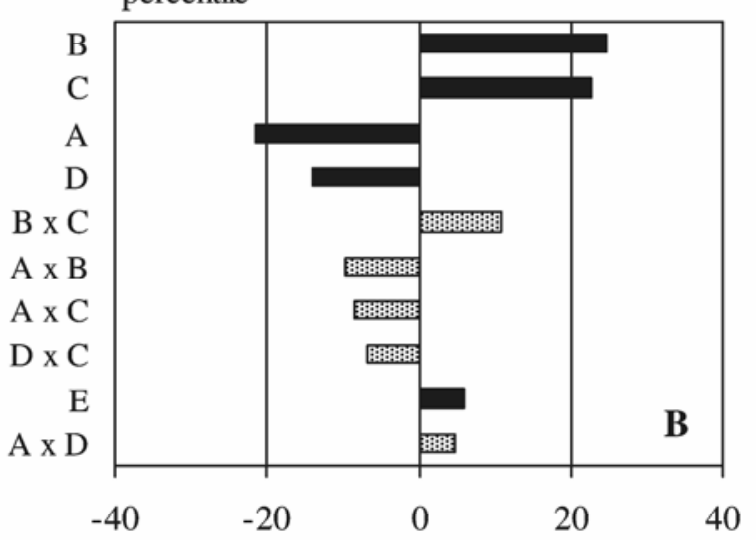

A = p_sampling, $B=s \_r i s k, C=s \_s w u s e$, $\mathrm{D}=\mathrm{s} \_$hygiene, $\mathrm{E}=\mathrm{e} \_$summer.

Incidental costs, median (million $€ /$ year)

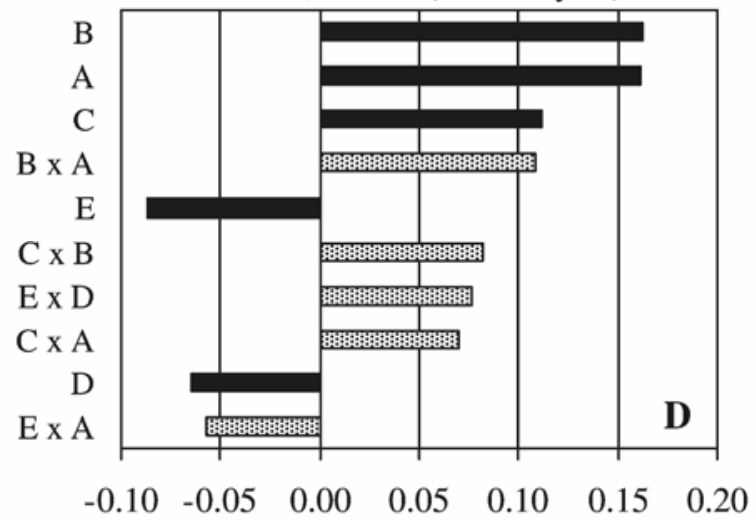

A = s_swuse, $\mathrm{B}=\mathrm{s} \_$risk, $\mathrm{C}=\mathrm{p} \_$probinf, $\mathrm{D}=\mathrm{s} \_$system, $\mathrm{E}=\mathrm{s} \_$hygiene.

Frequency of export losses (\%)

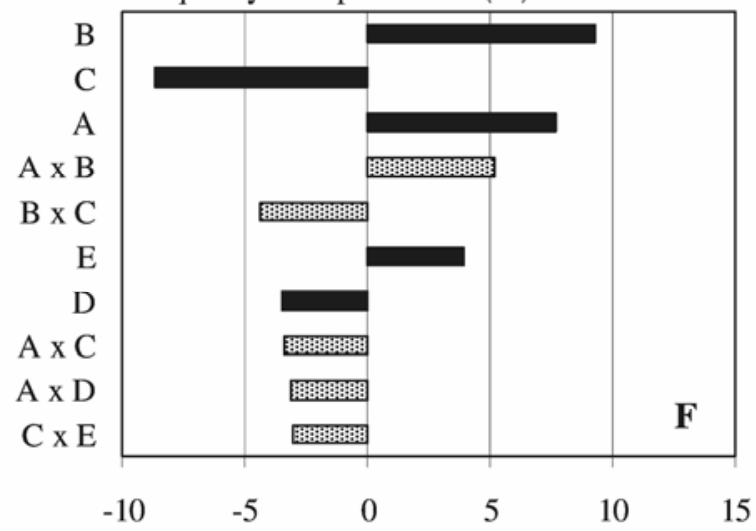

$\mathrm{A}=\mathrm{s} \_$swuse, $\mathrm{B}=\mathrm{s}$ _risk, $\mathrm{C}=\mathrm{p} \_$sampling, $\mathrm{D}=\mathrm{s} \_$hygiene, $\mathrm{E}=\mathrm{e} \_$summer.

Fig. 3. Ten highest ranked main effects and interactions per response variable, based on the R-5 design (all significant at $P<0.05$ ). Symbols A to E on the y axis denote the top five of factors in the R-4 design (A = highest ranked factor and so on). Explanation of bar patterns: black = main effect and dotted = interaction. Explanations of factor acronyms are provided in Table 1. 
fected" after detection of an infected lot (p_probinf). Thus, as the probability of brown rot infections increases, preventive measures become more important to curtail their spread, and the impact of reactive measures on incidental costs increases. The only response variable for which interactions do not play a significant role is the median of structural costs. Structural costs do not depend on brown rot incidence or the number of infections. They consist of two components, costs of monitoring and losses from restrictive regulations, which do not affect each other.

Validation of metamodels. The $R^{2}$ of the metamodels based on the R-4 design vary between 0.61 and 0.98 , indicating that the main effects of factors explain a considerable fraction of the variation in simulation outputs (Table 3). Metamodels based on the R-5 design, which also include two-factor interactions, explain almost $100 \%$ of the variation. Cross validation of all metamodels gives correlation coefficients ranging from 0.68 to 1.00 (Table 3), indicating a reasonable to excellent goodness of fit.

Scatter plots of the cross-validations of the metamodels based on the R-4 designs (Appendix II) show that most metamodels underestimate extremes while overestimating the middle range of simulation outputs. This is due to the fact that these metamodels include only main effects and do not account for higher-order effects. Moreover, the metamodels can give negative responses, whereas the simulation outputs have a minimum of zero. Including two-factor interactions causes the scatter plots to be more evenly distributed around the 1:1 line (Appendix II) and, thus, increases the predictive value of the metamodels. We conclude that the R-4 and R-5 metamodels are valid for their intended application, which is identification of important factors and quantification of their main effects and interactions, respectively.

Scenario studies. The government almost completely determines the cost of control but has minimal impact on brown rot incidence (Fig. 4A). In contrast, the sector has a large impact on brown rot incidence but has little influence on the costs of control. Confirming the results of the impact analysis, the average yearly number of infections and frequency of export losses in the scenarios are strongly correlated (Fig. 4B).

Upon a change in sector strategy, compared with the default sector strategy (A), average brown rot incidence changes with at least 10 infections per year, whereas the frequency of export losses changes threefold. These substantial effects largely result from a change in the probability of primary infection; a brownrot-minimizing strategy (B) of the sector reduces the number and likelihood of farms to illegally irrigate with surface water, whereas a cost-minimizing strategy (C) has the opposite effect. For a given strategy of the sector, the frequency of export losses can be reduced by a brown-rot-minimizing strategy of the government. The high sampling intensity in such a government strategy reduces the risk of extreme outbreaks. However, if the sector attaches greater importance to the minimization of brown rot incidence, the impact of a brown-rot-minimizing government strategy on the frequency of export losses decreases, while its impact on the costs of control remains the same. Thus, the cost-effectiveness of brown rot control by the government strongly depends on the strategy of the sector.

The extra scenarios $\mathrm{BC}^{\prime}$ and $\mathrm{C}^{\prime} \mathrm{B}$ give "extreme" results (Fig. $4)$. In $\mathrm{BC}^{\prime}$, the government prioritizes cost minimization regardless of the consequences for the risk of export losses while the sector minimizes brown rot incidence; in scenario $\mathrm{C}^{\prime} \mathrm{B}$, the opposite occurs. The results indicate that a government aiming at minimizing brown rot incidence cannot compensate for the negative consequences of a sector that aims at minimizing (private) costs of control. In contrast, a control policy aiming at cost minimization is acceptable as long as the sector's main objective is to minimize brown rot incidence. Thus, the sector can compensate for a reduction in brown rot control efforts by the government, but the reverse is not true.

TABLE 3. $R^{2}$ of the metamodels of all response variables based on the R-4 and R-5 designs, and correlation coefficients ( $\left.\hat{\rho}\right)$ resulting from cross validation of these models

\begin{tabular}{lcccc}
\hline & \multicolumn{2}{c}{ Metamodels R-4 design } & & \multicolumn{2}{c}{ Metamodels R-5 design } \\
\cline { 2 - 3 } \cline { 4 - 5 } Response variables & $R^{2}$ & $\hat{\rho}$ & $R^{2}$ & 0.98 \\
Median of yearly number of infections & 0.73 & 0.86 & 0.78 \\
90th percentile of yearly number of infections & 0.79 & 0.89 & 0.99 & 0.88 \\
Median of structural costs/year & 0.98 & 0.99 & 1.00 & 1.00 \\
Median of incidental costs/year & 0.61 & 0.78 & 0.98 & 0.68 \\
90th percentile of incidental costs/year & 0.65 & 0.80 & 0.93 \\
Frequency of export losses & 0.74 & 0.86 & 0.99 \\
\hline
\end{tabular}

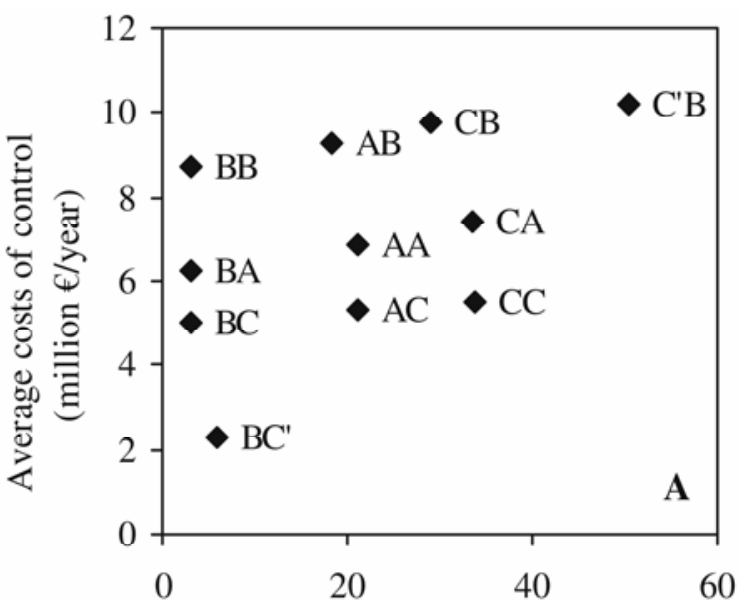

Average number of infections per year

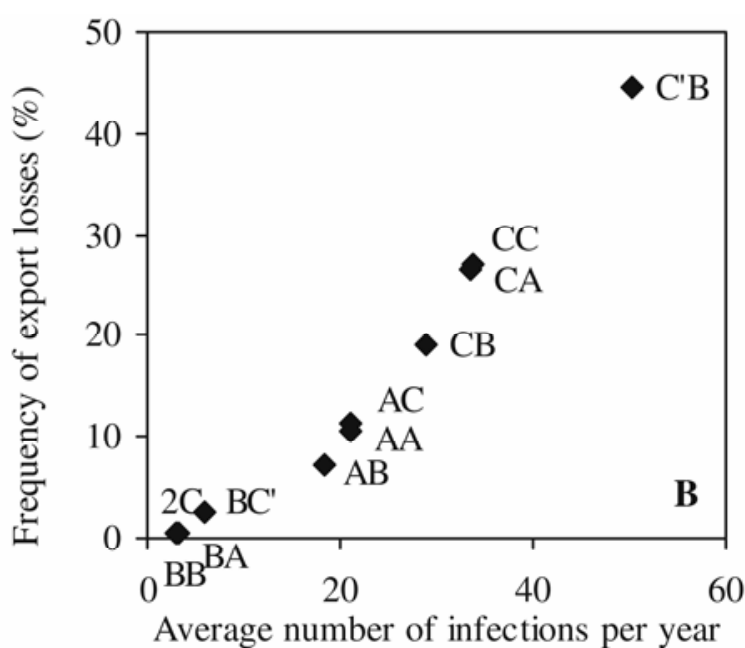

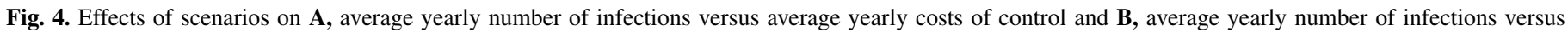
frequency of export losses. Scenarios are explained in Table 2. 
The cost-effectiveness of control compared with the default scenario (AA) can be increased by a shift in the strategy of the government toward the minimization of costs (AC), a shift in the strategy of the sector towards the minimization of brown rot incidence (BA), or a combination of these two strategies (BC and $\mathrm{BC}^{\prime}$ ) (Fig. 4). A shift in the strategy of the sector can reduce the average yearly number of infections by $\approx 75 \%$. A shift in the strategy of the government can reduce average costs of control by $\approx 2$ million euros per year. If both groups change their strategy, a reduction in costs of $>4$ million euros per year compared with the current situation can be achieved $\left(2 \mathrm{C}^{\prime}\right)$. Scenarios $2 \mathrm{C}$ and $2 \mathrm{C}^{\prime}$ together compose the cost-efficient set of scenarios. A scenario belongs to the efficient set if no alternative scenario leads to the same level of brown rot incidence with fewer costs (22). Thus, the two most cost-effective scenarios are those in which the sector minimizes brown rot incidence and the government minimizes costs.

\section{DISCUSSION}

The aim of this study was to quantitatively analyze the possibilities for increasing the cost-effectiveness of controlling quarantine diseases at the level of the production chain, using brown rot in the Dutch potato production chain as a case study. The impact analysis showed that the cost-effectiveness of brown rot control is determined, to a large extent, by a small number of government and sector factors. Sector factors characterizing farm hygiene and the likelihood of illegal use of surface water are of major importance, whereas most other sector factors, such as those related to machinery, storage, and transport, have minimal impact. By far the most important government factor is sampling strategy. Some exogenous and economic factors (e.g., factors determining the losses resulting from drought stress or the probability of a summer climate that is conducive to brown rot) can cause subtle differences in cost-effectiveness.

Interactions between policy and sector factors indicated a dependency between these two groups in the cost-effectiveness of control, which was confirmed by the scenario studies. Compared with the default scenario, the sector can reduce brown rot incidence by $>50 \%$ without a structural change in costs, while the government can reduce the costs of control by at least 2 million euros per year without affecting brown rot incidence. The largest increase in cost-effectiveness can be achieved if the sector recognizes its responsibility for avoiding introduction of brown rot (and other diseases) into the potato production chain; in this situation, a cost reduction of 4 million euros per year can be achieved. However, if actors in the sector aim at minimizing costs by actions that increase the risk of brown rot introduction, then even an intensive, costly sampling strategy cannot prevent a high level of brown rot incidence and frequency of export losses.

A caveat in the analysis is that sector changes that lead to reduced brown rot incidence are not costed. Adjustments such as improving hygiene and switching to a closed production system certainly bring along costs (e.g., costs of investment and labor). These costs, however, are not solely attributable to brown rot and, therefore, were not included in the simulation model. Likewise, certain policy measures, such as a national irrigation ban and defining lots grown on the same farm as a detected lot "probably infected," do not affect brown rot incidence in the model, which may not be a realistic assumption. In practice, these measures are imposed as a precaution to cover potential but as-yet-unidentified risks, which are not included in the model. These limitations of the bio-economic model should be kept in mind when interpreting simulated scenarios with respect to their cost-effectiveness.

The impact analysis presented in this article should not be interpreted as a sensitivity analysis. In a sensitivity analysis, all factors are changed over the same relative range, which enables a more objective comparison of factors effects. In contrast, the purpose of the impact analysis was to quantify the change in the incidence and costs of brown rot that may be caused by a realistic degree of change in factor levels. Thus, the measured impacts depend on the sensitivity of model outputs to the factors as well as the magnitudes of their ranges. Consequently, a factor with a small range may be declared unimportant, even though the simulation model is sensitive to changes in this factor. Nevertheless, for most response variables, the differences between effects of high- and low-ranked factors are such that increasing the range of low-ranked factors would not cause their effects to become as large as those of important factors.

The metamodels support the identification of potential costeffective scenarios, but they cannot replace the bio-economic model. One reason is that the effect of a factor on a response variable may be nonlinear, in which case the value of factor level 0 does not lie exactly in the center of values of the upper and lower levels. Furthermore, the upper and lower levels of the factors included in the impact analysis were standardized to +1 and -1 , but factor values that lie between the values of the upper and lower level may be difficult to standardize to a level between -1 and +1 . This is the case for categorical factors such as sampling strategy, in which case a scaling of levels between -1 and +1 is not possible at all. Consequently, the metamodels cannot quantify the cost-effectiveness of scenarios containing other than those that are characterized by factor levels included in the experimental designs.

The results of the impact analysis show the strengths of using DOE and metamodeling compared with simpler approaches. A commonly applied alternative is one-at-a-time (OAT) sensitivity analysis, in which one factor per scenario is increased or decreased. However, this approach does not take into account possible interactions between factors. As shown in this study, identification of interactions can provide relevant information for policymakers. For instance, because many sector and policy factors amplify each other's effects, the effects of a highly cost- or brown-rot-minimizing strategy on the cost-effectiveness of control will be larger than expected on the basis of main factor effects. Another strength of DOE is that it measures average factor effects over all levels of the other factors, whereas OAT measures only the local effect of factors.

This study illustrates how impact analysis and scenario studies can complement each other. An impact analysis reveals which factors are important and how these factors interact, but it does not provide insight into the overall effects of factors on the costeffectiveness of control. Important insights from the scenario studies, such as the conclusion that the most cost-effective control is achieved if the sector aims at minimization of brown rot incidence and the government aims at cost minimization, could not have been obtained on the basis of the impact analysis alone. On the other hand, in the absence of impact analysis, it would be difficult to define a small set of scenarios that provides insight into the relationship between sector and government behavior and cost-effectiveness of control, and it would remain uncertain whether the most influential variables were included in the scenarios. The impact analysis allows for a preselection of factors to include in the scenario studies, and provides a starting point for policymakers for defining other, possibly cost-effective scenarios.

The current study has shown how bio-economic modeling can support the efficient design of optimal control strategies against quarantine diseases. By quantifying the effect of factors on disease incidence and economic consequences, factors that play a dominant role in determining the cost-effectiveness of control can be identified. Moreover, results from the analysis in this article clearly show the interdependency between sector and government in reaching an optimal cost-effective approach toward controlling brown rot in the potato production chain. This quantitative evidence can be used to enhance private-public partnerships toward ecologically and economically sound brown rot management. 


\section{APPENDIX I}

Definition of factor levels. Policy factors. Most policy-related factors are categorical, and the extreme levels chosen represent likely alternatives when tightening or relaxing a measure. Where possible, these alternatives are based on past or proposed adjustments of measures. Some factors are binary, in which case either the upper or lower level equals the default level. Due to the threat

Number of infections per year, median

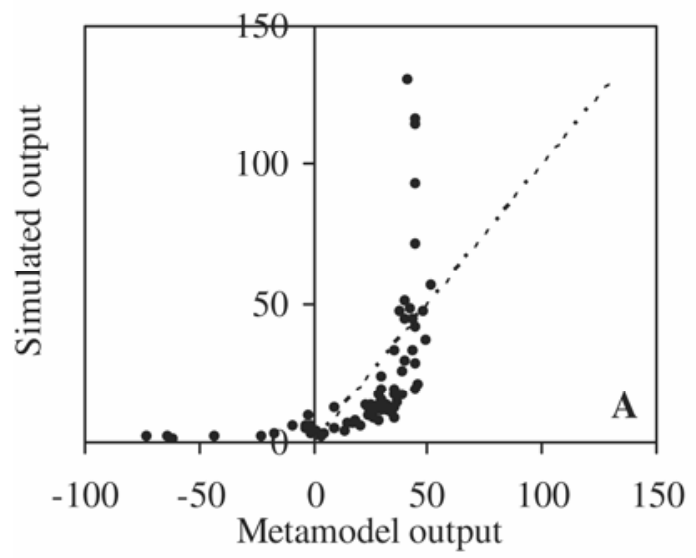

Structural costs, median (million $€ /$ year)

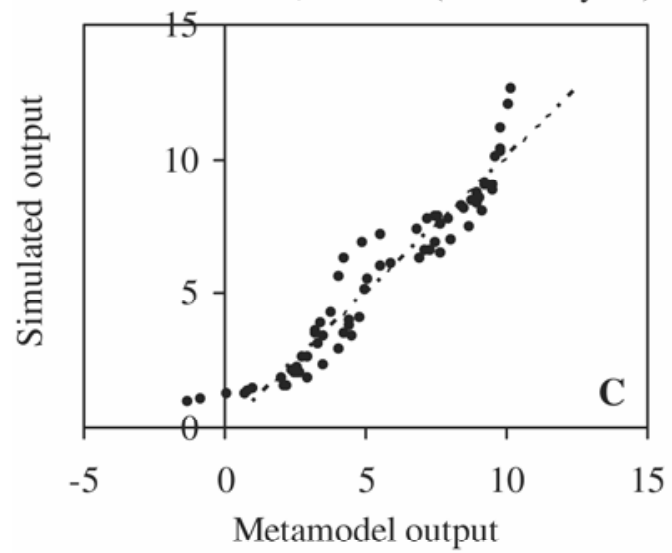

Incidental costs, 90th percentile (million €/year)

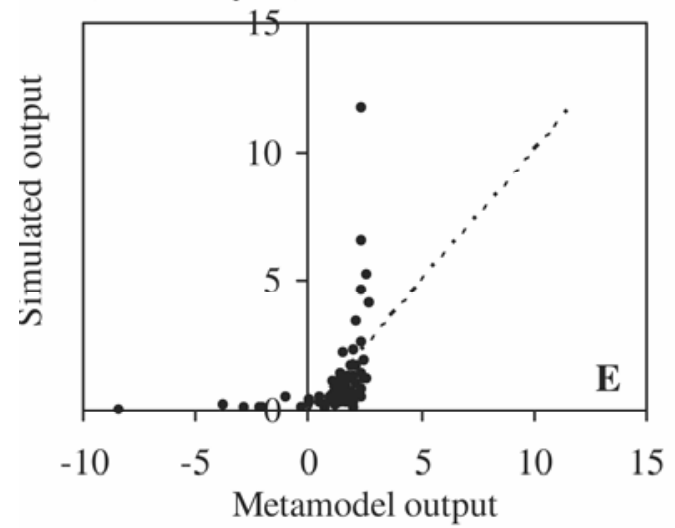

of potato diseases other than brown rot, minimum crop rotation schedule for potato is unlikely to be shortened.

Sector factors. Factors representing farm or sector characteristics were assumed to increase or decrease maximally by $50 \%$, which is in accordance with objectives and effectiveness of other recently implemented policies, such as the Dutch crop protection policy $(21,24)$. Machinery and a storage facility are, in practice, quasi-fixed assets; the corresponding factors therefore are as-

Number of infections per year, 90th

percentile

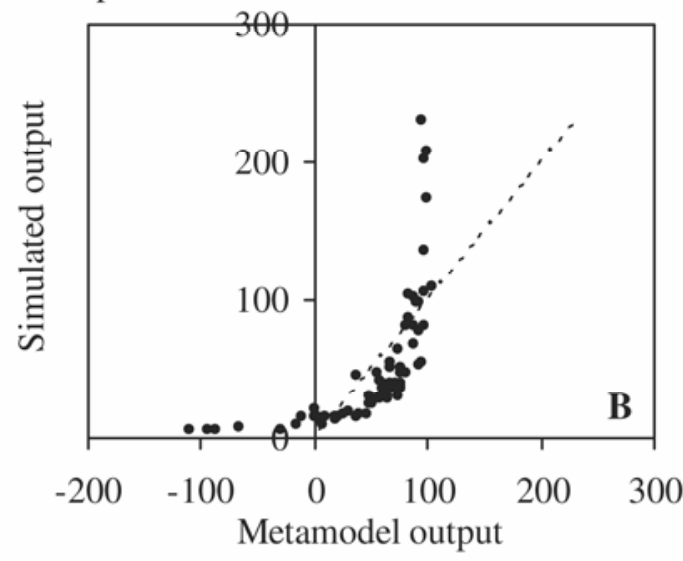

Incidental costs, median (million €/year)

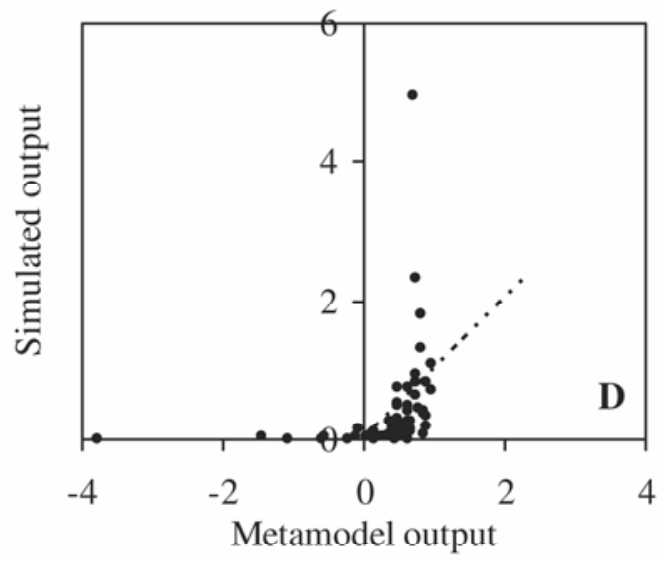

Frequency of export losses $(\%)$

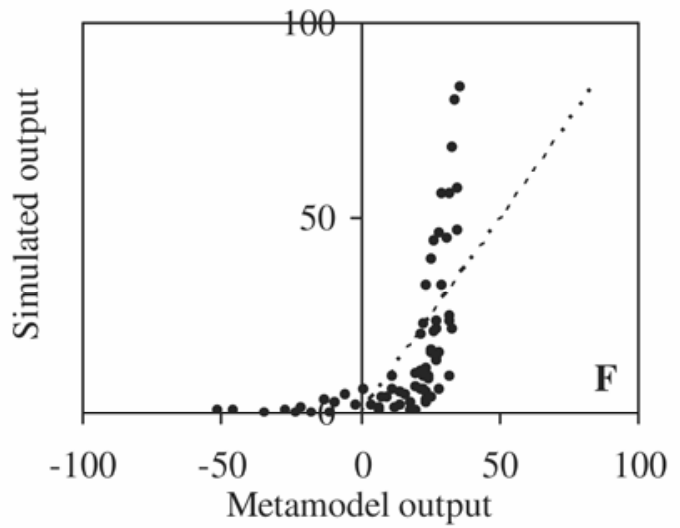

Fig. 5. Scatter plots of metamodel prediction and simulation realization, based on cross-validation results of the metamodels estimated from the scenarios in the R4 design. The dashed line represents the 1:1 line. 
sumed to vary over a range of, at maximum, 10\%. In theory, disinfection of trucks may occur at a frequency of almost $100 \%$; however, in practice, there always will be a few exceptions; therefore, the upper level of the corresponding factor was set at 0.999 .

Economic factors. Levels for potato prices were based on observed fluctuations of historical data on costs and prices $(7,8,13)$.

Number of infections per year, median

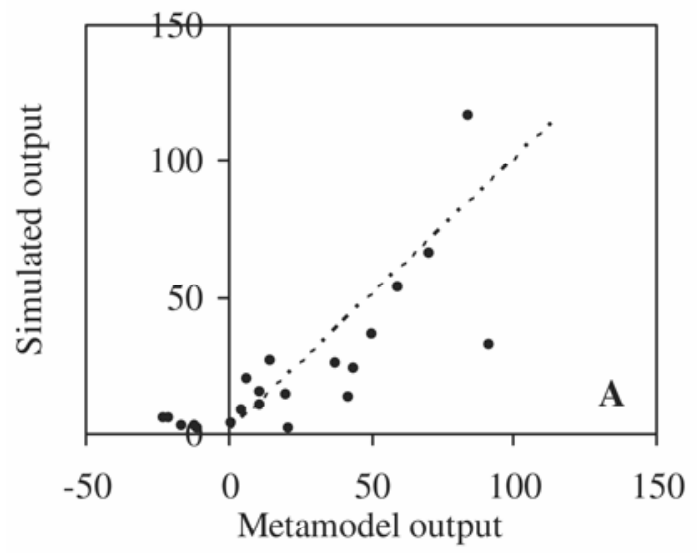

Structural costs, median (million €/year)

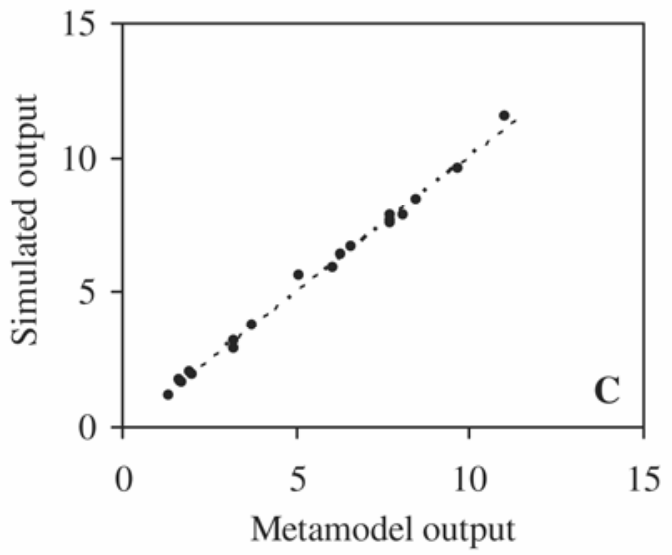

Incidental costs, 90th percentile (million $€ /$ year)

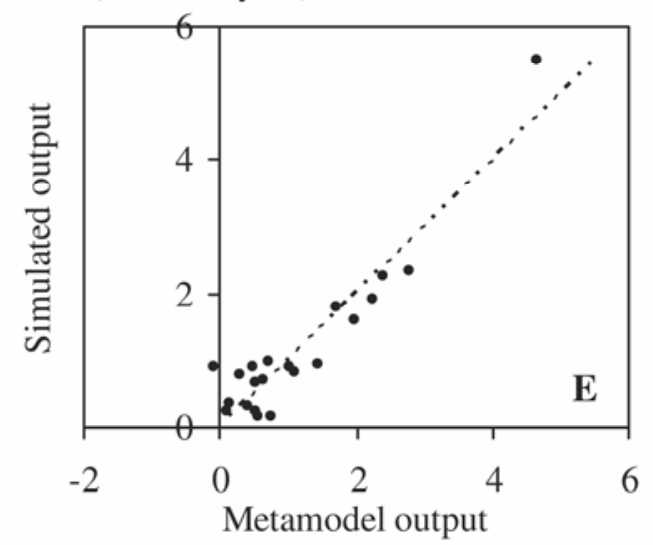

Levels for land rent prices were based on the observed general trend in Dutch land rent prices (7). In practice, certification, destruction, and production costs are semi-fixed and therefore assumed to increase or decrease at a maximum of $10 \%$. Price reduction due to quality loss is determined by trading companies and assumed to be increased or decreased at a maximum of $50 \%$, depending on future quality requirements of buyers.
Number of infections per year, 90th

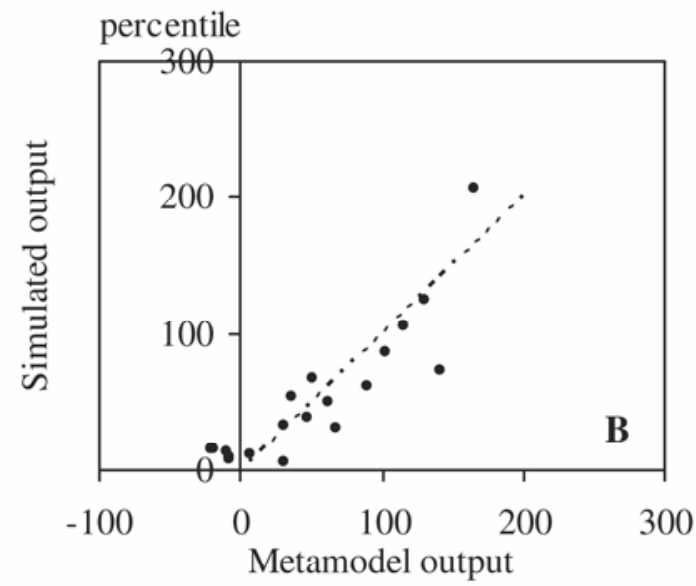

Incidental costs, median (million €/year)

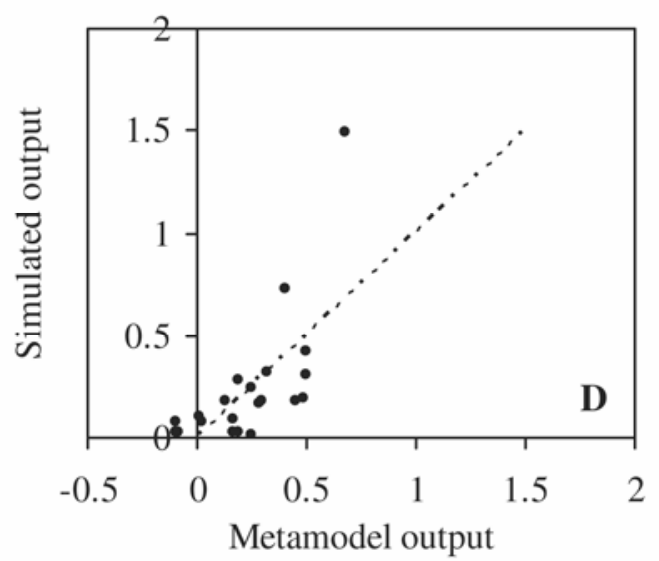

Frequency of export losses (\%)

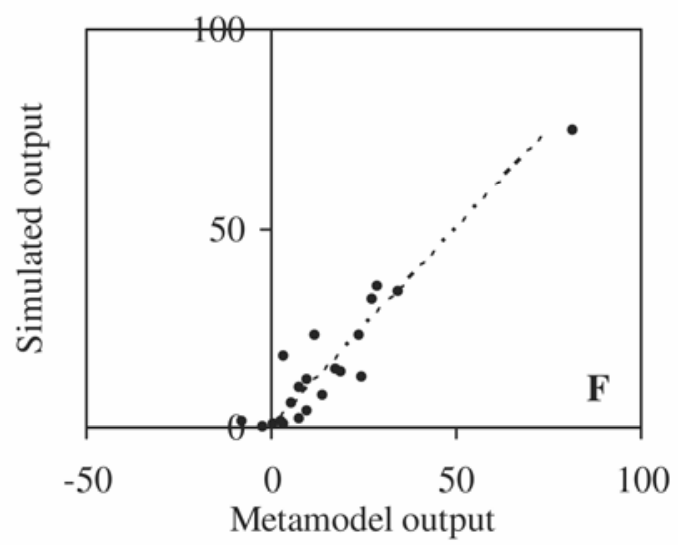

Fig. 6. Scatter plots of metamodel prediction and simulation realization, based on cross-validation results of the metamodels estimated from the scenarios in the R5 design. The dashed line represents the 1:1 line. 
TABLE 4. Default, lower, and upper factor levels for the distribution of hygiene levels over potato-growing farms

\begin{tabular}{|c|c|c|c|c|c|c|c|c|c|}
\hline \multirow[b]{2}{*}{ Potato grown ${ }^{\mathrm{a}}$} & \multicolumn{3}{|c|}{ Default level } & \multicolumn{3}{|c|}{ Lower level } & \multicolumn{3}{|c|}{ Upper level } \\
\hline & Low & Medium & High & Low & Medium & High & Low & Medium & High \\
\hline Only seed potato & 0.25 & 0.65 & 0.10 & 0.375 & 0.575 & 0.050 & 0.125 & 0.725 & 0.150 \\
\hline Ware (and seed) potato & 0.35 & 0.60 & 0.05 & 0.525 & 0.450 & 0.025 & 0.175 & 0.750 & 0.075 \\
\hline Starch (and seed/ware) potato & 0.45 & 0.55 & 0.00 & 0.675 & 0.325 & 0.000 & 0.225 & 0.775 & 0.000 \\
\hline
\end{tabular}

${ }^{a}$ Category of potato grown on farm.

TABLE 5. Default, lower, and upper factor levels for the distribution of type of machinery used by potato growing farms

\begin{tabular}{|c|c|c|c|c|c|c|c|c|c|}
\hline \multirow[b]{2}{*}{ Farm category } & \multicolumn{3}{|c|}{ Default level } & \multicolumn{3}{|c|}{ Lower level } & \multicolumn{3}{|c|}{ Upper level } \\
\hline & Private & Shared & Rent & Private & Shared & Rent & Private & Shared & Rent \\
\hline Closed production system & 0.8 & 0.2 & 0.0 & 0.72 & 0.26 & 0.0 & 0.88 & 0.12 & 0.0 \\
\hline$<10$ ha of potato & 0.39 & 0.23 & 0.38 & 0.351 & 0.231 & 0.418 & 0.429 & 0.229 & 0.342 \\
\hline $10-25$ ha of potato & 0.49 & 0.25 & 0.26 & 0.441 & 0.273 & 0.286 & 0.539 & 0.227 & 0.234 \\
\hline $25-50$ ha of potato & 0.61 & 0.27 & 0.12 & 0.549 & 0.319 & 0.132 & 0.671 & 0.221 & 0.108 \\
\hline $50-75$ ha of potato & 0.70 & 0.21 & 0.09 & 0.63 & 0.271 & 0.099 & 0.77 & 0.149 & 0.081 \\
\hline $75-100$ ha of potato & 0.75 & 0.20 & 0.05 & 0.675 & 0.27 & 0.055 & 0.825 & 0.13 & 0.045 \\
\hline$>100$ ha of potato & 1.0 & 0.0 & 0.0 & 0.90 & 0.10 & 0.0 & 1.0 & 0.0 & 0.0 \\
\hline
\end{tabular}

TABLE 6. Default, lower, and upper factor levels for prices of planted and harvested potato

\begin{tabular}{|c|c|c|c|c|c|c|c|c|c|c|c|c|}
\hline \multirow[b]{2}{*}{ Price category $^{\mathrm{a}}$} & \multicolumn{4}{|c|}{ Default level } & \multicolumn{4}{|c|}{ Lower level } & \multicolumn{4}{|c|}{ Upper level } \\
\hline & Seed & Ware & Starch & tbm & Seed & Ware & Starch & tbm & Seed & Ware & Starch & tbm \\
\hline Normal & 0.22 & 0.08 & 0.06 & 0 & 0.143 & 0.052 & 0.039 & 0.0 & 0.297 & 0.108 & 0.081 & 0.0 \\
\hline Infected & 0.02 & 0.02 & 0.06 & 0.06 & 0.013 & 0.013 & 0.039 & 0.039 & 0.027 & 0.027 & 0.081 & 0.081 \\
\hline Potato value & 0.24 & 0.0 & 0.0 & 0.16 & 0.156 & 0.0 & 0.0 & 0.104 & 0.324 & 0.0 & 0.0 & 0.216 \\
\hline Material value & 0.24 & 0.24 & 0.16 & 0.24 & 0.156 & 0.156 & 0.104 & 0.156 & 0.324 & 0.324 & 0.216 & 0.324 \\
\hline Price of material & 0.38 & 0.30 & 0.20 & 0.40 & 0.323 & 0.255 & 0.17 & 0.34 & 0.437 & 0.345 & 0.23 & 0.46 \\
\hline Profit & $\ldots$ & $\ldots$ & 0.0045 & $\ldots$ & $\ldots$ & $\ldots$ & 0.002925 & $\ldots$ & $\ldots$ & $\ldots$ & 0.006075 & $\ldots$ \\
\hline
\end{tabular}

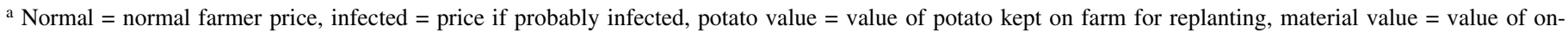
farm-produced planting material, price of material = purchase price of planting material, and profit = profit of starch industry.

Exogenous factors. The frequency of a conducive summer or fall is assumed to increase or decrease with, at maximum, one per 10 years. The potato acreage that suffers from drought stress is unlikely to decrease as long as the ban on surface water is in force. The probability of importing an infected lot can be minimized, but one cannot guarantee that this event will never occur; therefore, the lower level of this factor is set at 0.001 . The probability that an exported infected lot is detected abroad depends on monitoring intensity of importing countries. Given the large variety of countries to which Dutch potato tubers are exported, it is assumed that this probability increases or decreases at a maximum of $50 \%$.

\section{APPENDIX II}

Scatter plots resulting from cross validations are shown in Figures 5 and 6.

\section{APPENDIX III}

Levels of factors containing more than one subdivision are shown in Tables 4 to 6 .

\section{ACKNOWLEDGMENTS}

We thank the Dutch Plant Protection Service and the members of the brown rot response group for providing us with data and valuable feedback. Part of the funding for this work was provided by the Dutch Ministry of Agriculture, Nature, and Food Quality.

\section{LITERATURE CITED}

1. Banks, J., ed. 1998. Handbook of Simulation. John Wiley \& Sons, Inc., New York.
2. Breukers, A. 2006. Bio-economic modelling of brown rot in the Dutch potato production chain. Business Economics Group, Wageningen University, Wageningen, The Netherlands.

3. Breukers, A., Kettenis, D. L., Mourits, M., Van der Werf, W., and Oude Lansink, A. 2006. Individual-based models in the analysis of disease transmission in plant production chains: An application to potato brown rot. Agric. Syst. 90:112-131.

4. Breukers, A., Kettenis, D. L., Van der Werf, W., Mourits, M., and Oude Lansink, A. 2006. Technical documentation of a simulation model on brown rot dynamics in the Dutch potato production chain. Page 43 in: Quantitative Approaches in Systems Analysis. C. T. de Wit Graduate School for Production Ecology \& Resource Conservation, Wageningen, The Netherlands.

5. Breukers, A., Mourits, M., Van der Werf, W., and Oude Lansink, A. Costs and benefits of controlling quarantine diseases; A bio-economic modelling approach. Agric. Econ. (In press.)

6. Brown, C., Lynch, L., and Zilberman, D. 2002. The economics of controlling insect-transmitted plant diseases. Am. J. Agric. Econ. 84:279-291.

7. CBS. 2006. StatLine Databank: Centraal Bureau voor de Statistiek (Statistics Netherlands). Voorburg, The Netherlands.

8. Dekkers, W. A. 2001. Kwantitatieve Informatie: Akkerbouw en Vollegrondsgroenteteelt 2002 (Quantitative Information on Arable Farming and Outdoor Vegetable Production 2002). Applied Plant Research, Lelystad, The Netherlands.

9. Filipe, J. A. N., and Maule, M. M. 2004. Effects of dispersal mechanisms on spatio-temporal development of epidemics. J. Theor. Biol. 226:125141

10. Gottwald, T. R., Hughes, G., Graham, J. H., Sun, X., and Riley, T. 2001. The citrus canker epidemic in Florida: the scientific basis of regulatory eradication policy for an invasive species. Phytopathology 91:30-34.

11. Heikkila, J., and Peltola, J. 2004. Analysis of the Colorado potato beetle protection system in Finland. Agric. Econ. 31:343-352.

12. Holt, J., Colvin, J., and Muniyappa, V. 1999. Identifying control strategies for tomato leaf curl virus disease using an epidemiological model. J. Appl. Ecol. 36:625-633.

13. Hoogenboom, J. 2005. Historical Data on Dutch Potato Prices and Trade Volumes. HZPC Holland B.V., Joure, the Netherlands.

14. Irwin, M. E. 1999. Implications of movement in developing and deploying integrated pest management strategies. Agric. For. Meteorol. 
97:235-248.

15. Jones, R. A. C. 2004. Using epidemiological information to develop effective integrated virus disease management strategies. Virus Res. 100:5-30

16. Kleijnen, J. P. C. 2005. An overview of the design and analysis of simulation experiments for sensitivity analysis. Eur. J. Oper. Res. 164:287-300.

17. Kleijnen, J. P. C., and Sargent, R. G. 2000. A methodology for fitting and validating metamodels in simulation. Eur. J. Oper. Res. 120:14-29.

18. Kleijnen, J. P. C., and Van Groenendael, W. 1992. Simulation: A Statistical Perspective. John Wiley \& Sons, Inc., Chichester, UK.

19. Kogan, M. 1998. Integrated pest management: Historical perspectives and contemporary developments. Annu. Rev. Entomol. 43:243-270.

20. Law, A. M., and Kelton, W. D. 1991. Simulation Modeling and Analysis, 2nd ed. McGraw-Hill, Inc., Singapore.

21. LNV. 2004. Duurzame Gewasbescherming-Beleid Voor Gewasbescherming tot 2010 (Sustainable Crop Protection-Crop Protection Policy until 2010). Ministry of Agriculture, Nature, and Food Quality. (In Dutch)

22. Mas-Colell, A., Whinston, M. D., and Green, J. R. 1995. Microeconomic Theory. Oxford University Press, New York.

23. Otten, W., Filipe, J. A. N., Bailey, D. J., and Gilligan, C. A. 2003.
Quantification and analysis of transmission rates for soilborne epidemics. Ecology 84:3232-3239.

24. Schroën, G. J. M, Kok, T., and Horeman, G. H. 2000. Voortgangsrapportage 1999 Bestuursovereenkomst Uitvoering Meerjarenplan Gewasbescherming (Progress Report Agreement on the Implementation of the Multiple year Plan Crop Protection, 1999). Ministry of Agriculture, Nature, and Food Quality. (In Dutch)

25. Stacey, A. J., Truscott, J. E., Asher, M. J. C., and Gilligan, C. A. 2004. A model for the invasion and spread of rhizomania in the United Kingdom: Implications for disease control strategies. Phytopathology 94:209-215.

26. Teng, P. S., and Savary, S. 1992. Implementing the systems-approach in pest-management. Agric. Syst. 40:237-264.

27. Van den Bosch, F., Metz, J. A. J., and Zadoks, J. C. 1999. Pandemics of focal plant disease, a model. Anal. Theor. Plant Pathol. 89:495-505.

28. Willocquet, L., Elazegui, F. A., Castilla, N., Fernandez, L., Fischer, K. S., Peng, S. B., Teng, P. S., Srivastava, R. K., Singh, H. M., Zhu, D. F., and Savary, S. 2004. Research priorities for rice pest management in tropical Asia: A simulation analysis of yield losses and management efficiencies. Phytopathology 94:672-682.

29. Wu, C. F. J., and Hamada, M. 2000. Experiments: Planning, Analysis, and Parameter Design Optimization. Wiley Publ. Co., New York. 